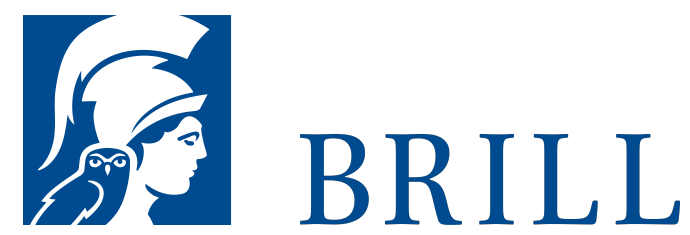

\title{
Wahrheit, Bedeutung und Glaube
}

Zum Problem des religiẽ $\llbracket$ sen Realismus

Author: Sebastian GÃab

Was ist das Wesen religi $\tilde{A}$ \ser Wirklichkeiten und wie zeigt es sich in religiÃ $\llbracket$ ser Sprache? Diese Frage wird beantwortet durch eine logisch-semantische Analyse verschiedener Bedeutungstheorien der religiÃ $\llbracket$ sen Sprache. Grundlage dafÃ $1 / 4$ r ist Michael Dummetts semantische Theorie des Realismus: Was RealitÃ at bedeutet, lãasst sich erklÃøren, indem wir erklãaren, was wir unter Wahrheit und Bedeutung verstehen, wenn wir Ã¹/4ber diese RealitÃat sprechen. Diese Theorie wird ausf $\tilde{1} 1 / 4$ hrlich dargestellt, kritisiert und weiterentwickelt. Das Ergebnis dieser Auseinandersetzung wird dann auf das Problem der religiã $\mid$ sen Sprache angewandt. Diverse antirealistische Ans Ãatze, die ein alternatives VerstÃăndnis religiẽ | ser Wirklichkeit und Sprache entwerfen, werden klassifiziert und kritisiert. Die Argumente in der Debatte werden herausgearbeitet und kritisch beleuchtet, um dann im Anschluss auf Basis der semantischen Theorie eine Reihe neuer Argumente zu entwickeln. Diese Argumente zeigen unter Berufung auf die bedeutungstheoretischen Grundlagen die Unhaltbarkeit des religiÃ $\llbracket$ sen Antirealismus. Die Idee einer religiÃ $\llbracket$ sen Wirklichkeit muss als solche ernst genommen werden.

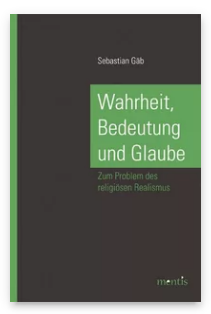

Pages: 247

Seiten

Language:

German

Subjects:

General,

Philosophy

Publisher: Brill | mentis

E-Book (PDF)

Released online: 19 Sep 2014

ISBN: 978-3-

95743-996-3

List price

Paperback

Publication date:

19 Sep 2014

ISBN: 978-3-

89785-229-7

List price 
For more information see brill.com

Order information: Order online at brill.com +44330 333 0049 | customerservices@brill.com Submission information: brill.com/authors

Titles published by Brill | Fink, Brill | mentis or Brill | Schöningh: +49(o)715413279216| brill@brocom.de 